\title{
Morpho-genetic studies on indigenous wheat genotypes at agro-climatic conditions of Haripur
}

\author{
Chaudhary Mohsin ${ }^{1}$, Sher Aslam Khan ${ }^{1}$, Raziuddin ${ }^{2}$, Fakharuddin $^{2 *}$, \\ Haneef Raza ${ }^{2}$, Sheraz Ahmed ${ }^{2}$ and Qamaruddin ${ }^{3}$ \\ 1. Department of Agriculture, University of Haripur, Khyber Pakhtunkhwa-Pakistan \\ 2. Department of Plant Breeding and Genetics, The University of Agriculture, Peshawar, Khyber Pakhtunkhwa- \\ Pakistan \\ 3. Department of Agricultural Extension Education and Communication, The University of Agriculture, Peshawar, \\ 25130, Khyber Pakhtunkhwa-Pakistan \\ *Corresponding author's email: fakharpbg@gmail.com \\ Citation \\ Chaudhary Mohsin, Sher Aslam Khan, Raziuddin, Fakharuddin, Haneef Raza, Sheraz Ahmed and Qamaruddin. \\ Morpho-genetic studies on indigenous wheat genotypes at agro-climatic conditions of Haripur. Pure and Applied \\ Biology. Vol. 5, Issue 4, pp768-772. http://dx.doi.org/10.19045/bspab.2016.50096
}

\begin{tabular}{llll}
\hline \hline Received: 10/03/2016 & Revised: 12/07/2016 & Accepted: 20/07/2016 & Online First: 08/08/2016 \\
\hline \hline
\end{tabular}

\section{Abstract}

This study was carried out at the research fields of The University of Haripur, during 2014-15 to evaluate three high yielding genotypes on the basis of their morphological characters using randomized complete block (RCB) design in three replications. Data were documented on ten traits viz., days to maturity (days), plant height $(\mathrm{cm})$, flag leaf area $\left(\mathrm{cm}^{2}\right)$, days to flowering initiation (days), stem girth $(\mathrm{mm})$, number of tillers plant ${ }^{-1}(\#)$, spike length $(\mathrm{cm})$, spikelet's spike $^{-1}(\#)$, seeds spike ${ }^{-1}(\#)$ and 1000-seed weight (g). Highly significant differences were detected among the tested wheat genotypes for all the studied traits. Data for days to maturity ranged from 166 to 171 days, for plant height 82.3 to $103.6 \mathrm{~cm}$, for flag leaf area 67.8 to 88.2 $\mathrm{cm}^{2}$, for days to flower initiation 104 to 114.7 days, for stem girth 4.8 to $5.2 \mathrm{~mm}$, for number of tillers plant ${ }^{-1} 12$ to 15.6 tillers, for spike length 11.9 to $12.0 \mathrm{~cm}$, for spikelets spike ${ }^{-1} 19.4$ to 22.3 spikelets, for seeds spike ${ }^{-1} 50.3$ to 58.2 seeds and for 1000 -seed weight 38.2 to $53.8 \mathrm{~g}$. Generally, high heritability was estimated for the studied traits which varied from $57 \%$ to $99 \%$. Days to flower initiation exhibited highest heritability value, whereas, minimum heritability was recorded for number of tillers plant ${ }^{-1}$. Based on the results of the current study, genotype Pirsabak-08 could be recommended for general cultivation in the agro-climatic conditions of Haripur.

Keywords: Wheat (Triticum aestivum L.); Genetic variability; Heritability; Haripur

\section{Introduction}

Wheat (Triticum aestivum L.) and its products are the main components of our daily diet. It's a source of staple food for many countries worldwide and enjoys special status due to its nutritional benefits. It consists of approximately 55\% carbohydrates and $20 \%$ of food calories ingested altogether, which makes it the major contributor of calories in the world's diet [1]. Likewise in Pakistan, wheat occupies around 9.039 million hectares of agricultural land with an annual outcome of 25.2856 million tons, makes Pakistan the $7^{\text {th }}$ 
largest producer in the world. It shares about $13.7 \%$ to the value added in agriculture and $3 \%$ to GDP of the country [2]. However, wheat production is not progressing with a reasonable pace due to many biotic and abiotic factors [3]. Hence, it has been a growing concern in wheat breeders to develop high yielding varieties with desirable genetic makeup to oppress the utilization burden of ever increasing population [4]. Selection is the basis of any breeding program. Effective selection increases the chances of success. Heritability, a measure of the phenotypic variance attributable to genetic causes, has predictive function of breeding crops [5]. High heritability coupled with genetic advance for important traits in wheat help the breeders in their selection programs and guide them to proceed in the right direction [6]. Although, research material comprised of high yielding varieties however, their relative performance in Haripur is unknown. Keeping in view the above mentioned facts, this research was initiated with the intentions to; i) evaluate wheat genotypes for morphological characters in the agroclimatic conditions of Haripur ii) to select promising genotype based on its performance for general cultivation in Haripur iii) to estimate heritability of various traits to improve grain yield in future breeding programs.

\section{Materials and methods}

Present experiment was carried out at the experimental farms of The University of Haripur, during crop season of 2014-15. Research material comprised of three high yielding genotypes viz., Pirsabak-05, Pirsabak-08 and Pirsabak-13. Genotypes were planted in RCB design with three replications in three rows per each genotype. Data were recorded on days to maturity, plant height, flag leaf area, days to flowering initiation, stem girth, number of tillers plant ${ }^{1}$, spike length, number of spikelet's spike ${ }^{-1}$, number of seeds spike ${ }^{-1}$ and 1000-seed weight. Analyses of variance for the said traits were done following procedure of Steel and Torrie [7]. Heritability in broad sense was estimated by calculating genetic and environmental variance components using the following formulas.

Genotypic variance $\left(\delta^{2} g\right)$

$$
=\frac{\boldsymbol{G M S}-\boldsymbol{E} \boldsymbol{M S}}{\boldsymbol{r}}
$$

Phenotypic variance $\left(\delta^{2} p\right)=\delta^{2} \mathrm{~g}+$ $\delta^{2} \mathbf{e}$

\section{Environmental variance $\left(\delta^{2} e\right)=E M S$}

Broad sense heritability $\left(h^{2}\right)$ was estimated using following formula:

$$
\boldsymbol{h}_{(B . S)}^{2}=\frac{\delta^{2} g}{\delta^{2} p}
$$

Where:

$\delta_{g}^{2}=$ Genotypic variance; $\quad \delta^{2}{ }^{2}=$ Phenotypic variance; $\delta^{2} e=$ Environmental variance; $h_{(B . S)}^{2}=$ Broad sense heritability

\section{Results and discussion Variance and mean performance}

Analysis of variance revealed that genotypes had considerable differences for all the studied traits (Table 2) indicating the presence of sufficient amount of variation among genotypes for these parameters. The broad spectrum of ranges for various traits also vindicated the diverse nature of genotypes. Our results are in line with the findings reported earlier by Cheema et al. and Thakur et al. [8, 9], who observed considerable variation for several morphological and yield parameters in wheat genotypes. Early maturing genotypes are desirable in various aspects as they have the ability to attain maximum possible seed yield at the first instance thereby, offering limited time space for the disease establishment [10]. Early maturing varieties have usually low harvest losses, nevertheless, they are often poor yielders. 
Days to maturity among genotypes varied from 166 to 171 days (Table.1). Maximum days to maturity (171 days) were exhibited by Pirsabak-08; however, genotype Pirsabak-13 took minimum days to mature (166 days). Plant height plays a vital role in yield and is influential in wheat breeding program. Mostly plant breeders are interested in selecting plants with semi-short stature due to their well response towards fertilizers and irrigation. Moreover, short framed plants usually show high tendency to withstand in winds and hence resist lodging [11]. Mean values for plant height ranged from 82.34 to $103 \mathrm{~cm}$. Genotype Pirsabak08 had the tallest plants $(103 \mathrm{~cm})$, whereas, short plant height $(82 \mathrm{~cm})$ was displayed by Pirsabak-05 (Table 1). Flag leaf area is the main photosynthetic spot during the grain filling stage, providing 41 to $43 \%$ of dry matter to the seed which eventually results an enhanced grain weight [12]. Average flag leaf area ranged from 67.8 to $88.2 \mathrm{~cm}^{2}$ (Table.1). Maximum flag leaf area (88.2 $\mathrm{cm}^{2}$ ) was observed in Pirsabak-08, whereas, small flag leaf area $\left(67.8 \mathrm{~cm}^{2}\right)$ was observed for genotype Pirsabak-13. Genotype Prisabak-05 took maximum days to flowering (114 days), whereas, least days to flower initiation (104 days) were displayed by genotype Pirsabak-13. On the other hand, maximum stem girth $(5.2 \mathrm{~mm})$ was observed in Pirsabak-08, whereas, minimum stem girth $(4.8 \mathrm{~mm})$ was displayed by Pirsabak13. Productive tillers are the key selection trait, which could directly raise the grain yield in wheat [6]. Plants with more tillers are the ultimate attraction for the breeders in irrigated condition. However, plants having few tillers could effectively cope in drought conditions and hence are well-suited for rain-fed areas. Mean value for number of tillers plant ${ }^{-1}$ varied from 12 to 12.7 tillers (Table 1). Genotype Pirsabak-13 exhibited maximum number of tillers plant ${ }^{-1}$ (12.7 tillers), whereas, least number of tillers plant $^{-1}$ (12 tillers) was observed for genotype Pirsabak-08. Spike length is an important component of yield which contributes towards the grain. Long spikes offer more room for grains and hence, will ultimately produce large number of seeds which is significantly reflected in yield. Spike length varied from 11.9 to $12 \mathrm{~cm}$. Maximum spike length $(12 \mathrm{~cm})$ was observed in Pirsabak-13, whereas, short length spikes $(11.9 \mathrm{~cm})$ were displayed by Pirsabak-08 (Table 1). Spikelets spike $^{-1}$ is important because it directly affects the yield. Genotypes with high number of spikelets spike ${ }^{-1}$ eventually result in high production [13]. Number of spikelets spike $^{-1}$ varies from 19.4 to 22.3 spikelets (Table 1). Maximum number of spikelets spike ${ }^{-1}$ (22.3 spikelets) was shown by Pirsabak-05, whereas, least number of spikelets spike $^{-1} \quad(19.4$ spikelets $)$ was recorded by genotype Pirsabak-08. Number of grains spike ${ }^{-1}$ is an important parameter in yield. Number of grains spike ${ }^{-1}$ varied from 50.3 to 58.2 grains (Table.1). Highest value of grains spike ${ }^{-1}$ (58.2 grains) was exhibited by genotype Pirsabak-05, whereas, least number of grains spike ${ }^{-1}$ (50.3 grains) was exhibited by genotype Pirsabak-13. Thousand grains weight is an important and usually decisive yield supporting trait used as key selection parameter to obtain high yield. Mean value for thousand grains weight ranged from 38.2 to $53.8 \mathrm{~g}$ (Table.1). Maximum seed weight $(53.8 \mathrm{~g})$ was exhibited by genotype Pirsabak-08, whereas, minimum 1000-seed weight (38.2 g) was displayed by genotype Pirsabak-13. 
Table 1. Mean values for the said parameters of wheat genotypes during 2014 -15

\begin{tabular}{|l|c|c|c|c|c|c|c|c|c|c|}
\hline Genotype & $\begin{array}{c}\text { DTM } \\
(\mathbf{d a y s})\end{array}$ & $\begin{array}{c}\text { PH } \\
(\mathbf{c m})\end{array}$ & $\begin{array}{c}\text { FLA } \\
\left(\mathbf{c m}^{\mathbf{}}\right)\end{array}$ & $\begin{array}{c}\text { FI } \\
(\mathbf{d a y s})\end{array}$ & $\begin{array}{c}\text { SG } \\
(\mathbf{m m})\end{array}$ & $\mathbf{N T P}^{-1}$ & $\begin{array}{c}\text { SL } \\
(\mathbf{c m})\end{array}$ & $\begin{array}{c}\mathbf{N S S}^{-1} \\
\mathbf{S S}^{-1}\end{array}$ & $\mathbf{1 0 0 0 - S W T}_{(\mathbf{g})}$ \\
\hline PIRSABAK-05 & 168 & 82.3 & 71.6 & 114 & 4.8 & 15.6 & 11.9 & 22.3 & 58.2 & 38.2 \\
\hline PIRSABAK-08 & 171 & 103.6 & 88.2 & 109 & 5.2 & 12.6 & 12.0 & 19.4 & 55.7 & 53.8 \\
\hline PIRSABAK-13 & 166 & 88.8 & 67.8 & 104 & 4.8 & 12.0 & 11.9 & 19.5 & 50.3 & 52.1 \\
\hline CV (\%) & 0.4 & 5.1 & 14.6 & 0.7 & 1.2 & 19.2 & 2.1 & 1.9 & 7.7 & 11.7 \\
\hline LSD (0.05) & 0.54 & 3.79 & 9.06 & 0.67 & 0.05 & 2.11 & 0.21 & 0.33 & 3.64 & 4.61 \\
\hline
\end{tabular}

DTM=Days to maturity, $\mathrm{PH}=$ Plant height, FLA $=$ Flag leaf area, FI=Flower Initiation, $\mathrm{SG}=$ Stem Girth, $\mathrm{NTP}^{-1}=$ Number Tiller Plant $^{-1}, \mathrm{SL}=\mathrm{Spike}$ length, $\mathrm{NSS}^{-1}=$ No. of spikelets spike ${ }^{-1}, \mathrm{SS}=$ Seed spike $^{-1}, 1000-\mathrm{SWT}=$ Thousand seed weight

\section{Heritability (Broad Sense)}

Data recorded on all the parameters exhibited high estimates of broad sense heritability, which ranged from 57 to $99 \%$ (Table 2). High heritability showed the important role of genetic variance in the heredity of the studied traits. It also indicates that studied traits were insensitive to the tested environment and hence selection for these traits in earlier generation would be effective if involved in a breeding program. Highest broad sense heritability of $99 \%$ was exhibited by days to flower initiation followed by days to maturity and number of spikelets spike ${ }^{-1}(98 \%)$. The present results are in agreement with the findings of Jedynski [14]. High broad sense heritability (94\%) was observed for stem girth and plant height. Similarly, moderate to high heritability was observed for number of tillers plant $^{-1}(57 \%)$, spike length $(58 \%)$, number of seeds spike $^{-1}(70 \%)$, flag leaf area $(72 \%)$ and 1000-seed weight (87\%). The high heritability estimates are indicative of the genetic role in the governance of these traits thus these traits could be fixed in early generations in a breeding program. Heritability increases with better inputs thus high heritability is evident of overall favourable environmental conditions for the studied genotypes. This also suggests that these genotypes could successfully be adapted to the new agro-climatic conditions of Haripur. Our findings are in conformity with the results reported by Thakur et al. and Kashif and Khaliq [9, 15], who noticed high heritability for the said parameters.

Table 2. Means Square value, Variance components and heritability $\left(h^{2}\right)$ for different parameters

\begin{tabular}{|l|c|c|c|c|c|}
\hline Traits. & GMS & EMS & $\mathbf{V g}$ & $\mathbf{V p}$ & $\mathbf{h}^{\mathbf{2}}$ \\
\hline Days to maturity & $18.78^{* *}$ & 0.45 & 18.63 & 19.07 & 0.98 \\
\hline Plant height & $365.20^{* *}$ & 21.57 & 358.01 & 379.58 & 0.94 \\
\hline Flag leaf Area & $354.69^{* *}$ & 123.18 & 313.63 & 436.81 & 0.72 \\
\hline Flower initiation & $85.34^{* *}$ & 0.67 & 85.12 & 85.79 & 0.99 \\
\hline Stem Girth & $0.15^{* *}$ & 0.01 & 0.15 & 0.16 & 0.94 \\
\hline No. of tillers plant $^{-1}$ & $11.23^{* *}$ & 6.67 & 9.01 & 15.68 & 0.57 \\
\hline spike length $^{\text {No. of spikelets spike }} \mathbf{1}^{-1}$ & $0.12^{* *}$ & 0.07 & 0.10 & 0.17 & 0.58 \\
\hline No. of seed spike $^{-1}$ & $8.04^{* *}$ & 0.17 & 7.98 & 8.15 & 0.98 \\
\hline 1000-Seed weight $^{*}$ & $48.57^{* *}$ & 17.97 & 42.58 & 60.55 & 0.70 \\
\hline
\end{tabular}

GMS=Genotype Mean Square; EMS=Error Mean Square; Vg= Genotypic variance; $\mathrm{Vp}=$ Phenotype variance; $\mathrm{h}^{2}=$ Heritability

\section{Conclusions}

Results revealed considerable genetic diversity among genotypes for the studied traits. All attributes manifested significant differences for genotypes having high broad sense heritability. Hence, genotypes having high heritability could be used in perfecting various important plant attributes in future 
cultivar development program. Overall, genotype Pirsabak-08 dominated other genotypes in various traits and could be considered for general cultivation in the agro-climatic conditions of Haripur.

\section{Authors' contributions}

Conceived and designed the experiments:

SA Khan, Performed the experiments: C Mohsin, Analyzed the data: Raziuddin, Contributed reagents/ materials/ analysis tools: H Raza \& Qamaruddin, Wrote the paper: Fakharuddin \& S Ahmed.

\section{References}

1.Breiman A \& Graur D (1995). Wheat evolution. Israel J Plant Science 43(2) 8598.

2.Pakistan Bureau of Statistics (2014). Ministry for Food and Agric. Govt. of Pakistan, Islamabad.

3. Reynolds MP, Nagarajan S, Razzaque MA \& Ageeb OAA (2001). Application of physiology in wheat breeding. Mexico, $D F$, CIMMYT.

4.Uddin F, Mohammad F \& Ahmed S (2015). Genetic Divergence in wheat Recombinant Inbred lines for yield and yield components. American Eurasian. J Agric \& Environ Science 15(9): 1854-1859.

5.Songsri P, Jogloy S, Kesmala T, Vorasoot N, Akkasaeng C, Patanothai A \& Holbrook CC (2008). Heritability of drought resistance traits and correlation of drought resistance and agronomic traits in peanut. Crop Science 48(6): 2245-2253.

6.Memon S, Qureshi MUD, Ansari BA \& Sial MA (2007). Genetic heritability for grain yield and its related characters in spring wheat (Triticum aestivum L.). Pakistan $J$ Bot 39(5): 1503-1509.

7.Steel RGD \& Torrie JH (1984). Principles and Procedures of Statistics: A Biometrical
Approach, 2nd edition McGraw Hill Book Co., New York

8. Cheema NM, Mian MA, Ihsan M, Rabbani G \& Mahmood A (2006). Studies on variability and some genetic parameters in spring wheat. Pakistan J Agri Sciences 43: $1-2$.

9. Thakur SK, Pandey RI \& Kandalkar VS (1999). Genetic association and variability for grain yield and other quantitative characters in F2 population of wheat crosses. Adv Plant Science 12(1): 237- 239.

10. Calderini DF \& Reynolds MP (2000). Changes in grain weight as a consequence of de-graining treatments at pre-and postanthesis in synthetic hexaploid lines of wheat (Triticum durum $x$ T. tauschii). Functional Plant Biol 27(3): 183191.

11. Khan IM, Tila M, Fazle S, Muhammad \& Syed TS (2007). Agronomic evaluation of different bread wheat (Triticum aestivum $\mathrm{L}$ ) for terminal heat stress. Pakistan J Bot 39(7): 2415-2425.

12. Ibrahim HA \& Elenein RA (1977). The relative contribution of different wheat leaves and awns to the grain yield and its protein content. Zeitschrift fuer Acker und Pflanzenbau.

13. Muhammad F, Denial H, Shahzad k \& Khan H (2001). Heritability estimates for yield and its components in wheat. Sarhad J Agric 17 (2): 227234.

14. Jedynski S (2001). Heritability and pathcoefficient analysis of yield components in spring wheat. Grupy Problemowej Wodowli Pszenicy. Proceeding of Symposium, Zakopane, Poland, No. 218/219: 203-09

15. Kashif M \& Khaliq I (2004). Heritability, correlation and path coefficient analysis for some metric traits in wheat. Inter J Agric Biol 6(1): 138-142. 